

\title{
SOME MISCONCEPTIONS ON CELL STRUCTURE AND FUNCTION HELD BY A-LEVEL BIOLOGY STUDENTS: IMPLICATIONS FOR CURRICULUM DEVELOPMENT
}

\author{
E. M. Z. Tambo, J. P. Mukaro, and J. Mahaso.
}

Science Education In-service Teacher Training (SEITT) Programme

Department of Science and Mathematics Education

University of Zimbabwe

\section{Abstract}

Knowledge about cell structure is vital in students' understanding of cell functions. It also plays a central role in their understanding of structure and function in organisms. This research is part of a bigger survey which analysed misconceptions held by students, teachers and those in commonly used Biology texts, with particular reference to misconceptions on cell structure and function. This paper reports on results ohrained from open-ended questionnaires relating to A-level biology students' misconceptions about cell structure. A total of 72 students participated in the study. The study revealed that some students hold misconceptions about cell structure and function that are likely to influence their understanding of other concepts if left un-addressed.

\section{Context of the Study}

The prevalence of erroneous concepts among students presents a serious obstacle to learning in Biology. To promote effective and meaningful learning, we need to identify the causes of such misconceptions and find ways to rectify them or prevent them from occurring.

Misconceptions may arise when the teaching fails to induce a conceptual change in the student (Ausubel, 1963). Certain prerequisite concepts are necessary for a learner to develop genuine understanding on a certain concept. If these do not exist, it would be difficult if not impossible for the learner to understand the new concept. Unfortunately this is often the case for a large 
class with children of varicd abilities. A teacher normally plans his or her teaching according to the structure of the subject course, assuming that, on the basis of the previous courses taught, the students have already mastered the prerequisitc ideas. This assumption is often unrealistic as, in one way or another, the students may not have assimilated the prerequisite ideas into their cognitive structures, which are necessary for a meaningful understanding of the new topic.

In curriculum planning, it is therefore necessary not only to consider the logical structure of the subject matter, but also to take into account the students' prior knowledge. The teacher cannot assume that; after going through previous courses, the children would have necessarily acquired these ideas.

Yager (1991) argues that students who often score well in standardised tests are often found to have problems in successfully integrating or contrasting memorised facts and formulas with the experiences they acquire in day-to-day life. In recent years the education system in Zimbabwe has been largely criticised for its failure to produce graduates who are able to apply their knowledge and skills in industry and commerce despite having passed their examinations well (Nziramasanga, 1999). Part of this criticism centres on the fact that the current school curricula is failing to help students have a good conceptual understanding. It is argued that because of this inadequate conceptual understanding, students fail to be creative and to take initiative in the place of work. While it is appreciated that various other factors also impact on student understanding, it is however important to have a deeper analysis into how both teachers and students understand some key biological concepts which influence their understanding of the subject in general. Some research on biological topics has been done, for example, photosynthesis (Simpson \& Arnold, 1982; Bell, 1985); genetics (Hackling, 1982; Stewart, 1983) and mutation (Albaladejo and Lucas, 1988). Little research of this kind however appears to have been done in - the African context.

\section{Purpose and Research Questions}

This paper is part of a broader survey which seeks to identify the relationship between misconceptions held by students, teachers, and those found in commonly used A-level biology textbooks. The paper focuses on inisconceptions about cell structure held by A-level biology students. Concepts related to cell structure and function play a.central role in the development and understanding of other biological concepts especially those related to structure and function of the organism. Biology students' failure to learn biological con- 
cepts, meaningfully results from the existence of misconceptions that act as obstacles to meaningful understanding.

The study was centred on the following main research question:

What misconceptions do A-level biology teachers and students hold about cell structure and function?

\section{Methodology}

\section{Sample}

Seventy-two lower sixth form students participated in this research. The students were from eight randomly selected schools from Masvingo and Mashonaland. West Provinces in Zimbabwe. The students were of mixed ability and were both male and female aged between 16 and 18 years.

\section{Instruments and Procedure}

Results reported in this paper largely come from open-ended questionnaires given to the students. Two-tier multiple-choice tests and interviews were however also used to collect data from the students and teachers. Because the research is on-going, results reported in this paper to some extent lack triangulation.

The data collected were analysed qualitatively for misconceptions held by the students and the responses were tabulated.

\section{Analysis and Discussion of Results}

This section presents and discusses the results obtained from the open-ended questionnaire survey. Five questions were presented to the students and the results from these will be presented and discussed.

The first question required students to identify micrographs of (a) plant cell, (b) bacterial cell, (c) Endoplasmic Reticulum, (d) Golgi Apparatus, (e) Mitochondrion and (F) Animal Cell. Two of these choices (a) and ( $f$ ) were considered as correct responses and students who indicated both were considered to have made a complete identification while those who only identified onewould be considered to have made a partial identification. 
E. M. Z. Tambo: J. P. Mukaro; J. Mahaso.

Table 1.Frequency of Responses to Question 1(a) Students' Identification of Typical Cells From Electron Micrographs

\begin{tabular}{lll} 
& $\%$ of students & $\begin{array}{c}\text { Example of Reasons } \\
\text { for Choice }\end{array}$ \\
\hline Complete identification (A and F) & $27.3 \%$ & \\
Partial identification (A only) & $21.2 \%$ & $30.3 \%$ \\
Partial identification (F only) & $27.3 \%$ \\
Incorrect identification (B) & $9 \%$ \\
Incorrect identification(C) & $9 \%$ \\
Incorrect identification (D) & $9 \%$ \\
\hline Incorrect Identification (E) &
\end{tabular}

Analysis of data indicated that students had difficulties in identifying a typical cell from electron micrographs. The table above reveals that $27 \%$ of the students completely failed to identify typical cells from the micrographs. These students therefore appear not to have the requisite knowledge to identify typical cells from electron micrographs. A reason for this could be that most students have never had practical experience in identifying micrographs, as conditions for such observations are almost non-existent in Zimbabwean secondary schools. During teaching it would also appear that teachers rarely emphasise the observation of electron micrographs.

The fact that quite a considerable number of students identified a prokaryotic cell indicated that students may not be clear of what a typical eukaryotic cell looks like. The clearly defined cell wall of the prokaryote may have tempted some students to think that perhaps it was a plant cell. The failure to distinguish the other organelles however indicates that there is inadequate understanding or skills to differentiate what constitutes a cell. The reasons given by the students as indicated in Table 2 below reveals the nature of some of the misconceptions held by students.

From the results it can be seen that most students identified $F$ as the typical cell. This probably resulted from the fact that the nucleus was clear in the central part of the cell. As we will see in later responses student tend to associate cells with the existence of a central nucleus. This relates to how cells are often presented in textbooks. 


\section{Table 2: Categories Reason Given by Pupils for Their Answer Choice to Question 1}

\section{Choice of Answer Category of Reason}

$A$ and $F$

- The electron micrograph illustrates the nucleus as a dark portion. There is existence of a cell wall/membrane as well as membrane bound organelles in the cell (e.g. mitochondria, endoplasmic reticulum)

- A shows a cell wall, cell membrane and a central vacuole while $\mathrm{F}$ shows a cell membrane and distinct nucleus

- Presence of a nucleus and some organelles that can only be viewed under an electron microscope (ribosomes, endoplasmic reticulum, lysosomes)

A Only - Consist of numerous membrane bound organelles

- A typical cell consist of numerous organelles each of which is bound within a membrane

- The shape and presence of organelles indicate that it is a typical ceil

F Only

- There is a nucleus as shown by the dark sport and a cell membrane that surrounds the cell

- F has a cell membrane, nucleus, cytoplasm an vacuoles

- It has a nucleus, endoplasmic reticulum, mitochondria and cytoplasm

- F looks like a complete animal cell and the rest look like organelles from cells

- It seems to have a nucleus in the middle and other organelles found in cells

- The cell has a dark nucleus

- It has all the details of the structure of a cell, with the cell wall, membrane as well as membrane bound organelles

- B appears to have a membrane and cell organelles

C

- No reasons

D

- D visibly shows all cell organelles

- The Golgi apparatus is clearly visible in D

E

- No reasons 


\section{E. M. Z. Tambo; J. P. Mukaro; J. Mahaso.}

Some reasons given by students reveal misconceptions. The largest number of incorrect choices indicated B as the typical eukaryotic cell. As indicated earlier on, students who made this choice appear to have been attracted by the presence of an outer wall and disregarded the presence of other structures. As will be seen later on, this tends to relate to the fact that students tend to associate cell structure with the presence of a wall or membrane. This unfortunately is a limited view of what constitutes a cell.

Students who chose C (endoplasmic reticulum) and D (Golgi apparatus) appear to have done so through guess-work as no reasons were provided. Such students appear to have very limited skills in identifying cell structures from electron micrographs. To an observer it would appear that these two micrographs were clearly not cells. The fact that a number of students chose them under scores the importance of not making assumptions when assisting students in developing concepts. As Driver (1983) propoșes, it is always important to ensure that students' prior conceptions are taken into consideration before new concepts are addressed.

Table 3 and 4 below came mainly from the following questions:

2. Write down the first three words that come to your mind when you hear the expression cell structure.

3. Write down three sentences about the structure of a cell.

Table 3: Frequency of Identification of First Three Words Related to Cell Structure

Word Identified

Cell membrane

Nucleus

Cytoplasm

Shape/structure

Organelles

Function

Type
Frequency of Identification

44

40

30

30

30

20

2

The table reveals that students mainly tend to associate cell structure with the 
existence of a cell membrane and a nucleus. This should probably be expected to be common since representations and diagrams of cells in books always show the outer line together with the dark nucleus in the middle. In a similar manner the existence of cytoplasm and organelles was also quite common in the responses. In this case it could be said that when students think about cell structure, they make reference to the different components of the cell. Some of the responses also indicated that some students tend to relate the structure of a cell to its function, while the relationship between the type of cell and the structure is rather uncommon.

In constructing sentences about cell structure, the results revealed that students could have some misconceptions. While a large number of responses showed correct use of the word cell wall or membrane, a significant number tended to use the words inappropriately. Below is a list of examples of sentences in which words related to cell structure were used correctly and incorrectly.

\section{Table 4: Usage of Words Related to Cell Structure}

\section{Word Used Example of Correct Usage Example of Erroneous Usage}

Cell wall

Nucleus

Nucleus

Organelle

Cytoplasm

Function

$$
\begin{aligned}
& \text { - Cells have different } \\
& \text { organelles which have } \\
& \text { different functions } \\
& \text { - Cell organelles are bound } \\
& \text { by membranes }
\end{aligned}
$$

- The nucleus is the centre of control for all cellular activities

-Plant cells have cell walls

None

- The nucleus is the largest part of a cell and consists of many organelles

- Most cells have a nucleus at the centre of the cell for instructions

- Organelles control the structure by keeping the cell firm

- Organelles influence the structure of cells

- The cytoplasm is the liquid part of the cell which acts as a transport medium up of a phospholipid bi-layer as well as some proteins

- All cells have cytoplasm and contain organelles
- Cell structure is adapted to its function

- Cell differ in relation to their function

None 
Cell membrane

Shape/structure
- Cells have a membrane which is semi-permeable

- Cells have a membrane

- Cell shape may vary in relation to its function
- The plasma membrane is

. coated with proteins

- Plant cells are hexagonal and animal cells are spherical

The incorrect usage of words in sentences reveals misconceptions as indicated by the examples in the above table. For example the notion that plant cells are hexagonal while animal cells are spherical is likely to emanate from how the cells are often presented in textbooks. This can also be said for students' perception that the nucleus is always in the centre of the cell.

The construction of sentences with words about cell structure further helped to reveal students misconceptions about the notion of cell structure.

\section{Table 5: Frequency of Correct/Incorrect Use of Words About Cell Structure in Constructing Sentences}

Word used in constructing sentence

\begin{tabular}{lcc} 
& Correct Use & Incorrect \\
\hline Cell wall/membrane & 12 \\
Nucleus & 50 & 12 \\
Shape/Size & 32 & 8 \\
Cytoplasm & 4 & 8 \\
Function & 8 & 0 \\
Organelles & 20 & 36 \\
Type & 28 & 2 \\
\hline
\end{tabular}

Frequency
In constructing sentences the most frequently used words were cell wall and cell membrane. From this it can be inferred that students tend to relate the cell structure to the cell wall or membrane. Since the cell wall and membrane surround the cell and are often well-presented in diagrams, it is perhaps not surprising that students would tend to associate these with providing the structure for the cell. As we saw earlier on in the first questions, once students identify something that appears to represent a cell wall or membrane, they automatically think that they have identified a typical cell. This kind of misconception results in students making incorrect identifications. 


\section{Zimbabwe Journal of Educational Research}

The word organelle had the highest frequency of incorrect usage with the majority of sentences with incorrect usage suggesting that cell organelles have some control on the shape and/or structure of the cell. While it can be argued that organelles have some influence on cell structure, it can however not be said that they actually control the structure. Language problems could perhaps be attributed to this, as some students may not see the difference between having an influence on the cell structure and controlling it.

\section{Conclusions}

This part of the study has revealed that students appear to have some serious misconceptions about cell structure. Failure to identify a typical cell by several students indicates limited knowledge about the basic features of typical cells. There is also an apparent lack of knowledge and skill of identifying features in electron micrographs.

Experienced teachers often underestimate the importance of prior knowledge in the learning process. Their expertise in the subject matter often makes them think that good teaching and willingness to learn will automatically ensure meaningful learning. Teachers often fail to see things from the student's point of view and thus fail to appreciate the learning difficulties experienced by some of the students in understanding and mastering new concepts if they lack certain prerequisite concepts. From the results presented in this paper it can be said that students' failure to identify typical cells or to write correct sentences in relation to cell structure, results from lack of prerequisite knowledge and skills about these concepts.

The way teachers present concepts to students and the way diagrams are presented in textbooks and other printed material appears to have an influence on how students develop their concepts. It is therefore important to ensure that both teachers and printed material are free from misconceptions so that these do not influence conceptual development in the students.

Further studies on teachers' misconceptions and those in texts are therefore crucial. Teachers need to be made aware of how to identify misconceptions and to use methods that can help to address these misconceptions.

\section{References}

Albaladejo C. \& Lucas A. M. (1988). Pupils' meanings for mutation. Journal of Biological Education, 22(3), 215-218 
E. M. Z. Tambo: J. P. Mukaro; J. Mahaso.

Ausubel, D. (1963). The psychology of meaningful verbal learning. New York:Holt. Renehart \& Winston.

Bell, B. F. (1985). Students' ideas about plant nutrition: What are they? Journal of Biological education, 19(3), 213-218.

Driver, R. (1983). The pupil as a scientist. St Edmunds: St Edmundsbury Press.

Hackling, M. (1982). Understanding of inheritance concepts. Australian Science Teachers'Journal, 28(1), 13-20

Nziramasanga, C. T. (1999). Report of the Presidential Commission of Inquiry into Education and Training. Harare: Government Printers.

Tema, B. O. (1989). Rural and urban African pupils' alternative conceptions of animal. Journal of Biological Education, 23(3), 199-206.

Yager, R (1991). Constructivist learning. The Science Teacher, 53-57 


\section{(c) (1) (9)}

This work is licensed under a

Creative Commons

Attribution - NonCommercial - NoDerivs 3.0 License.

To view a copy of the license please see:

http://creativecommons.ora/licenses/bv-nc-nd/3.0/ 